УДК 661.728; 542.91; 544.23

\title{
ПОЛИДЕНТАТНЫЙ АДСОРБЕНТ НА ОСНОВЕ ЛЬНЯНОЙ ЦЕЛЛЮЛОЗЫ, МОДИФИЦИРОВАННОЙ ГИПЕРРАЗВЕТВЛЕННЫМ ПОЛИЭФИРОПОЛИБЕНЗОИЛТИОКАРБАМАТОМ
}

(C) А.-М.П. Эриандес ${ }^{1}$, А.Ф. Максимов ${ }^{1}$, А.А. Жукова ${ }^{1}$, Д.А. Кудряшова ${ }^{1}$, К.С. Момзякова М.П. Кутырева $^{2}$, А.Р. Гатаулина ${ }^{2}$, Г.А. Кутырев ${ }^{* * *}$

${ }^{1}$ Казанский национальный исследовательский технологический университет, ул. К. Маркса, 68, Казань, 420015 (Россия), e-mail: genkutyrev@mail.ru

${ }^{2}$ Казанский фредеральный университет, Химический институт им. А.М. Бутлерова, ул. Кремлевская, 18, Казань, 420008 (Россия)

\footnotetext{
* Полный текст статьи опубликован: Эрнандес А.-М.П., Максимов А.Ф., Жукова А.А., Кудряшова Д.А., Момзякова К.С., Кутырева М.П., Гатаулина А.Р., Кутырев Г.А. Полидентатный адсорбент на основе льняной целлюлозы, модифицированной гиперразветвленным полиэфирополибензоилтиокарбаматом // Химия растительного сырья. 2021. №2. C. 79-85. DOI: 10.14258/jcprm.2021027503.

** Автор, с которым следует вести переписку.
} 


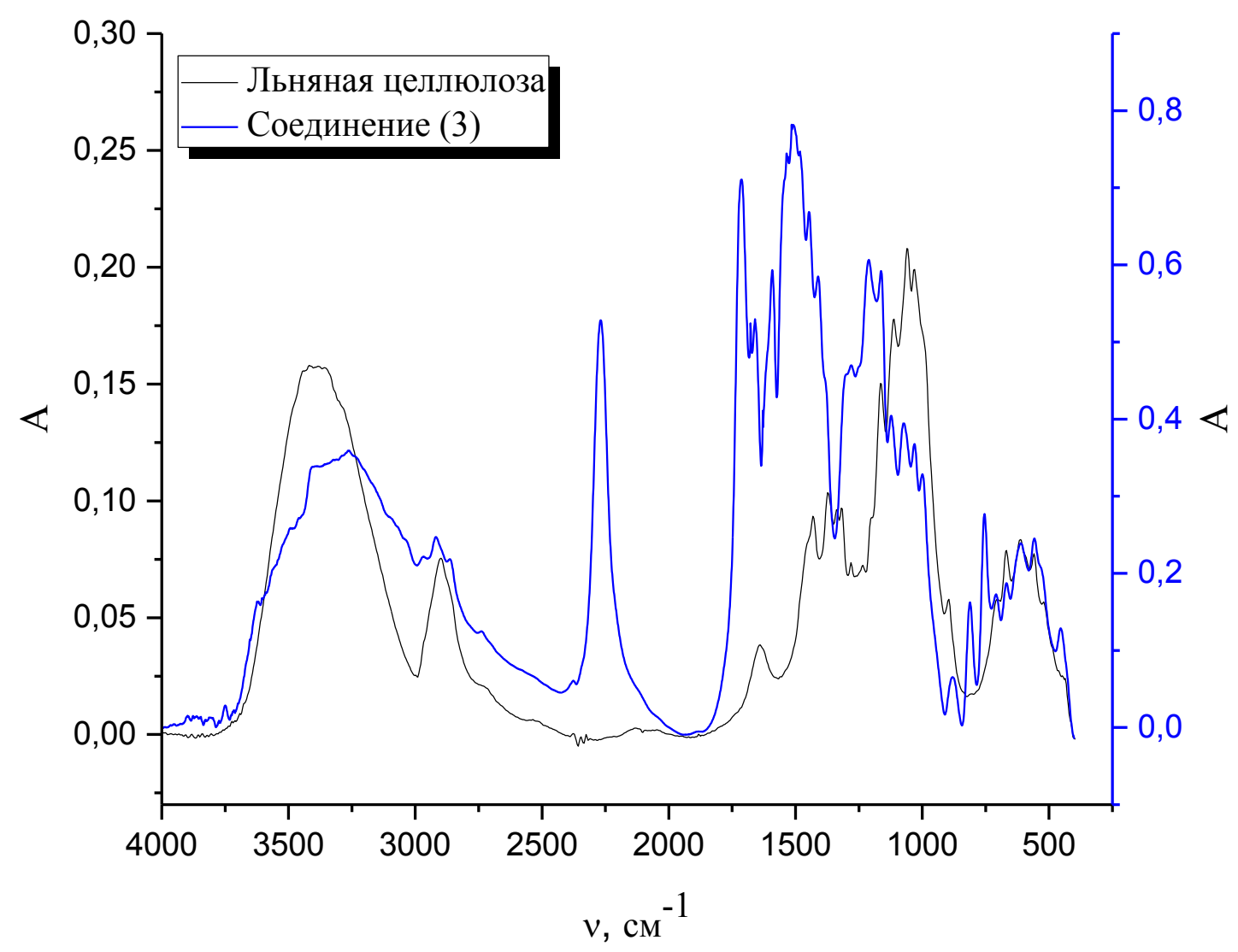

Рис. 1. ИК-спектр соединения 3 и льняной целлюлозы 1

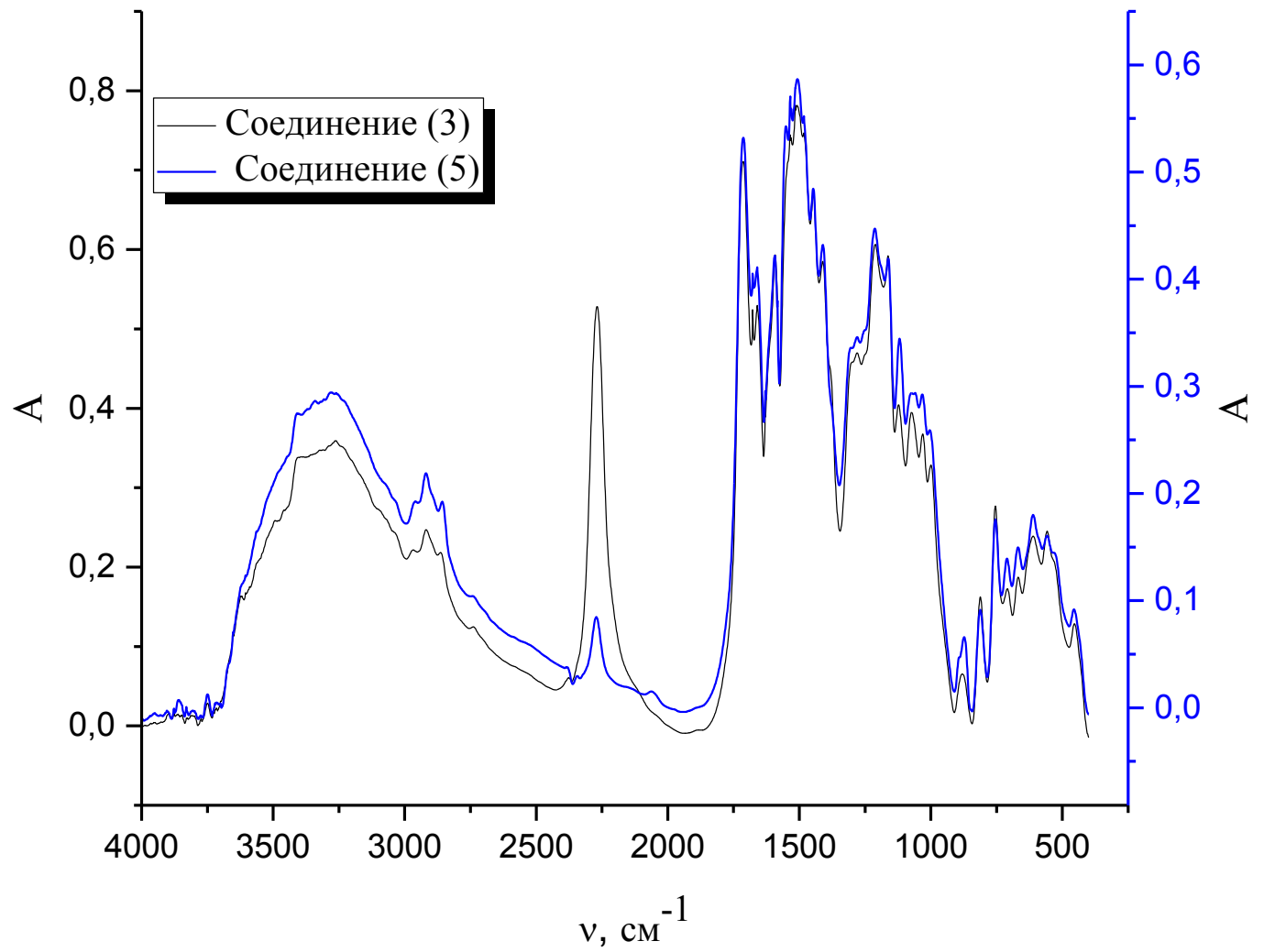

Рис. 2. ИК-спектр соединения 3 и соединения 5 


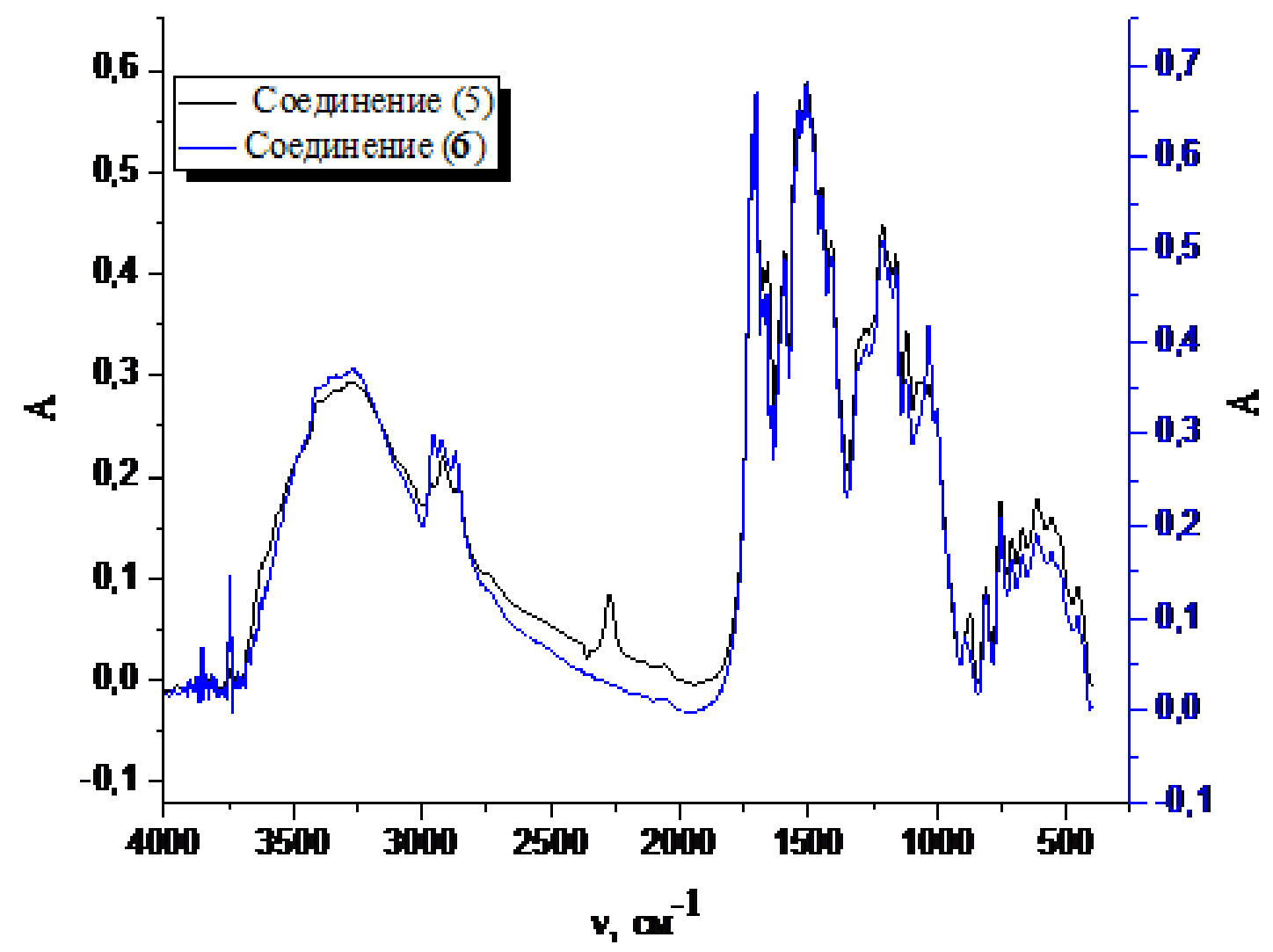

Рис. 3. ИК-спектр соединения 5 и соединения 6

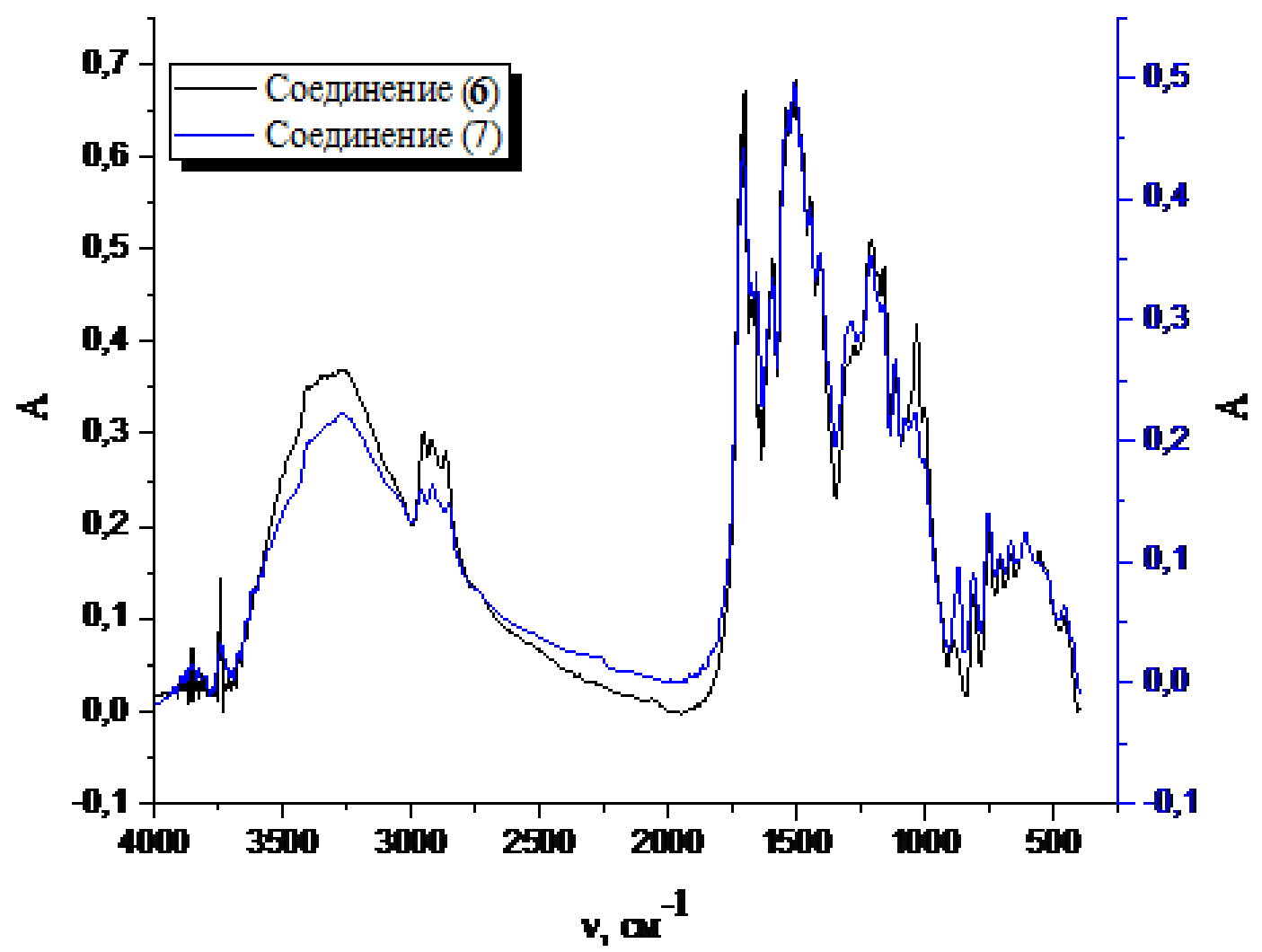

Рис. 4. ИК-спектр соединения 6 и соединения 7 




Рис. 5. ИК-спектр соединения 6 и соединения 8 